\title{
A study of etched track anisotropy in apatite
}

\author{
Surinder SINGH, Dilbag SINGH, A. S. SANDHU and H. S. VIRK \\ Department of Physics, Guru Nanak Dev University, Amritsar, India
}

\begin{abstract}
The etched track work on samples cut from different planes of apatite crystal is carried out in order to study the anisotropic etching behaviour of the crystal. The variation of the etched pit characteristics with crystallographic orientations is observed. The effect of the anisotropic etching on the age determination is reported. The etching conditions are determined for different planes using $\mathrm{HNO}_{3}$ as the track etchant.
\end{abstract}

\section{Introduction}

The most important advancement in the history of solid state nuclear track detectors (SSNTD) is the discovery of chemical etching for track revelation (Price and Walker, 1962). Since then the solid state nuclear track detectors have gained popularity in diverse fields such as anthropology, archaeology, geochronology, biology, medical sciences and industrial technology (Fleischer et al., 1975). In geochronology the technique is generally used for radiometric age determination of minerals and rocks.

Though a lot of work has been reported on dating minerals and rocks using track etch technique, little attention has been paid to the fundamental track etching characteristics of minerals and how these may affect the dating technique in routine use.

The classic description of track etching in terms of $\mathrm{V}_{\mathrm{T}}$, the track etch rate, $\mathrm{V}_{\mathrm{G}}$, the bulk etch rate, and etching efficiency, $\eta$ for a surface is well known (Fleischer et al., 1975). This description has proved extremely useful in understanding track etching in isotropic materials such as glasses and plastics; but the etching behaviour of natural minerals is more complicated. Since the atomic spacing is very variable along different crystallographic orientations in the anisotropic mineral and as the damage density is controlled in part by the spacing of atoms ionized along the path of a charged particle such as fission fragment, it follows that $\mathrm{V}_{\mathrm{G}}, \mathrm{V}_{\mathrm{T}}$ and hence $\eta$ (which is controlled by the ratio $\mathrm{V}_{\mathrm{T}} / \mathrm{V}_{\mathrm{G}}$ ) might be different for tracks in different orientations.

Durrani et al. (1974) have examined the effects of anisotropic $\mathrm{V}_{\mathrm{G}}$ in meteorite studies using bronzite and feldspar. Gleadow (1978) has reported work on track etch anisotropy in natural sphene. But with these important exceptions there have been 
very few studies of this type, because for many track etching applications simple detectors like glasses and plastics are generally used. In fission track dating one has to use natural detectors available in the form of uranium bearing minerals. Most of these minerals are anisotropic and would be expected to have complicated track etching characteristics. This anisotropic etching behaviour can affect the fission track age of the mineral.

In the present work an attempt has been made to study the track etch anisotropy in apatite and to observe its effect on fission track dating of this mineral. Apatite crystal procured from Quebec Lavel Museum and of Wakefield area in Canada has been used for such studies. This work for track etching and age determination has been

\section{PLANES}

I. $(0001)$

2. $(10 T 1)$

3. (0|Tि)

4. $(1 \overline{1} 00)$

5. (10T0)

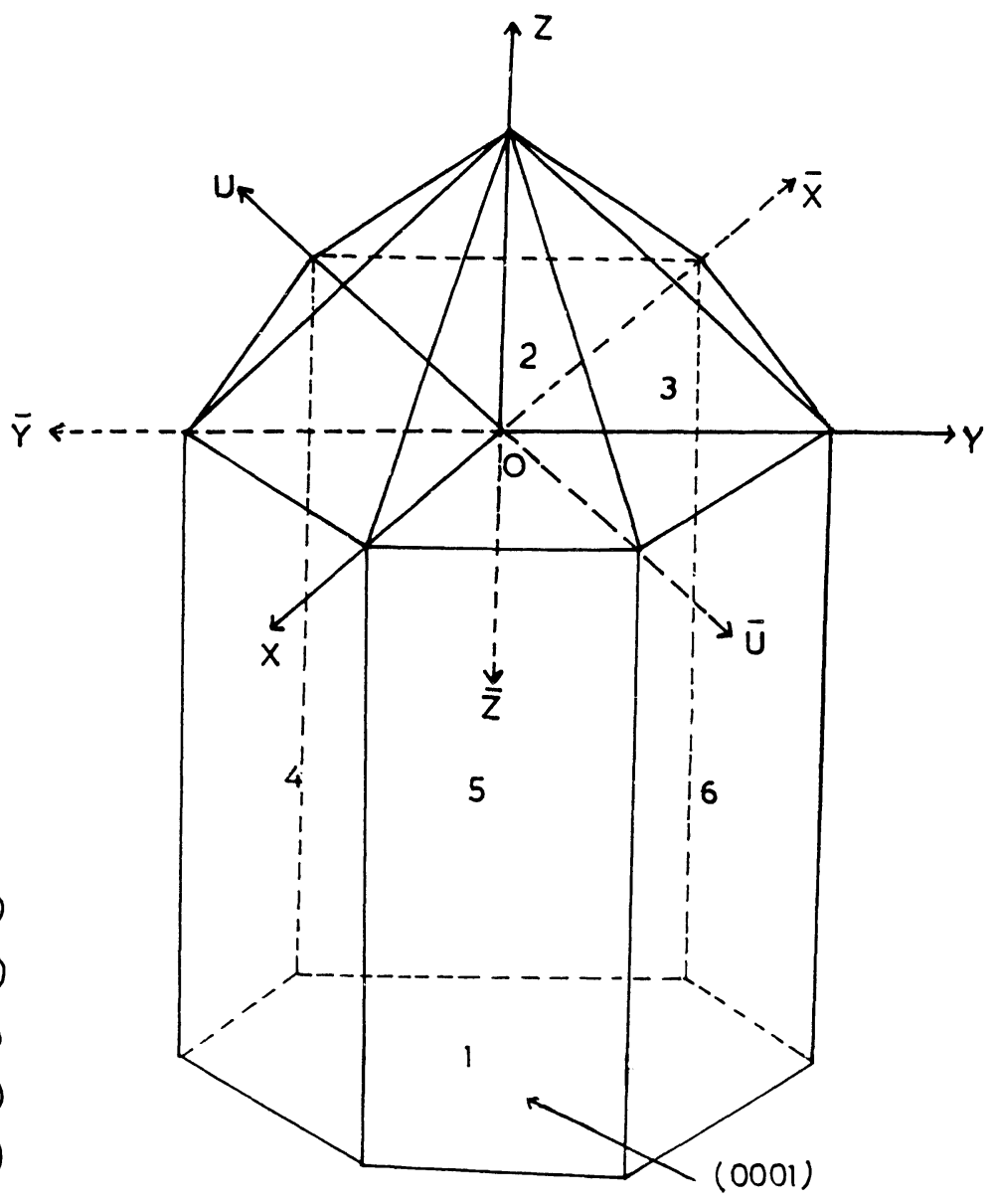

6. (01T0)

FIG. 1. Apatite crystal showing various planes. 
done on different planes cut from the crystal.

Apatite is a calcium phosphate mineral which occurs as six sided columnar crystal as shown in Fig. 1. More fission track ages have been obtained for apatite than for any other mineral. This is because of the availability of this mineral in suitable forms, can be ground and polished easily and has high etching efficiency for track revelation.

\section{Experimental procedure}

\section{(a) Sample preparation}

The apatite used in the present work has a large crystal having about $8 \times 1.5 \mathrm{~cm}^{2}$ as the area of the crystal surface. In order to cut the different planes of the apatite crystal, it was marked with $\mathrm{X}, \mathrm{Y}, \mathrm{U}$ and $\mathrm{Z}$ axis. $\mathrm{X}, \mathrm{Y}$ and $\mathrm{U}$ are inclined at $120^{\circ}$ with each other and $Z$ axis is perpendicular to all these axis. The planes (10 11$),(01 \overline{1} 1)$, (1 $\overline{1} 00),(10 \overline{1} 0),(01 \overline{1} 0)$ and $(0001)$ cut from the crystal were taken for study.

(b) Measurement of the bulk etch rate, $V_{G}$, the track etch rate, $V_{T}$ and etching efficiency, $\eta$, on different planes of apatite crystal

Samples from different faces of the crystal to be used for the study of $\mathrm{V}_{\mathrm{G}}, \mathrm{V}_{\mathrm{T}}$ and $\eta$ were heated at a temperature of $530^{\circ} \mathrm{C}$ for one and a half hour to remove fossil trackes. These samples were then fixed on the glass slide with the help of araldite. These samples were ground with emery powders of mesh size varying from 100 to 600 $\mu \mathrm{m}$ and were polished with cerium oxide powder. The samples were then irradiated with $\mathrm{Cf}^{252}$ fission fragment source in $2 \pi$ geometry. These were then etched in $6 \%$ $\mathrm{HNO}_{3}$ at room temperature for various time intervals. The projected length and diameter of tracks were measured at each etching time for different planes under an Olympus binocular microscope at a magnification of $1500 \mathrm{X}$. These measurements were made using a calibrated ocular scale provided in the microscope and twenty tracks were taken for observations on each crystal surface. The results for the variation of track length and track diameter with etching time for different planes are shown in Figs. 2 and 3 respectively. The bulk etch rate, $V_{G}$, was calculated from the slope of the curve etching time versus track diameter and is equal to one half of the rate of increase of diameter of a track. The track etch rate, $\mathrm{V}_{\mathrm{T}}$, was calculated on the assumption that $\mathrm{V}_{\mathrm{T}}$ remains constant for very small etching times, during which a small segment of particle trajectory is etched out (Fleischer et al., 1975, N. P. Singh et al., 1984). The relation between the track etch rate, $\mathrm{V}_{\mathrm{T}}$, and the etched track length $\mathrm{L}$, for an etching time, $t$, is given by:

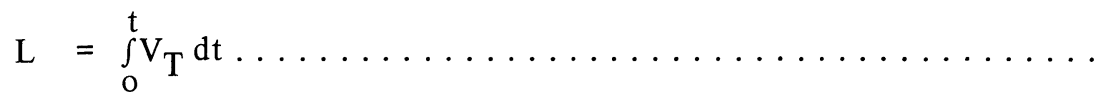




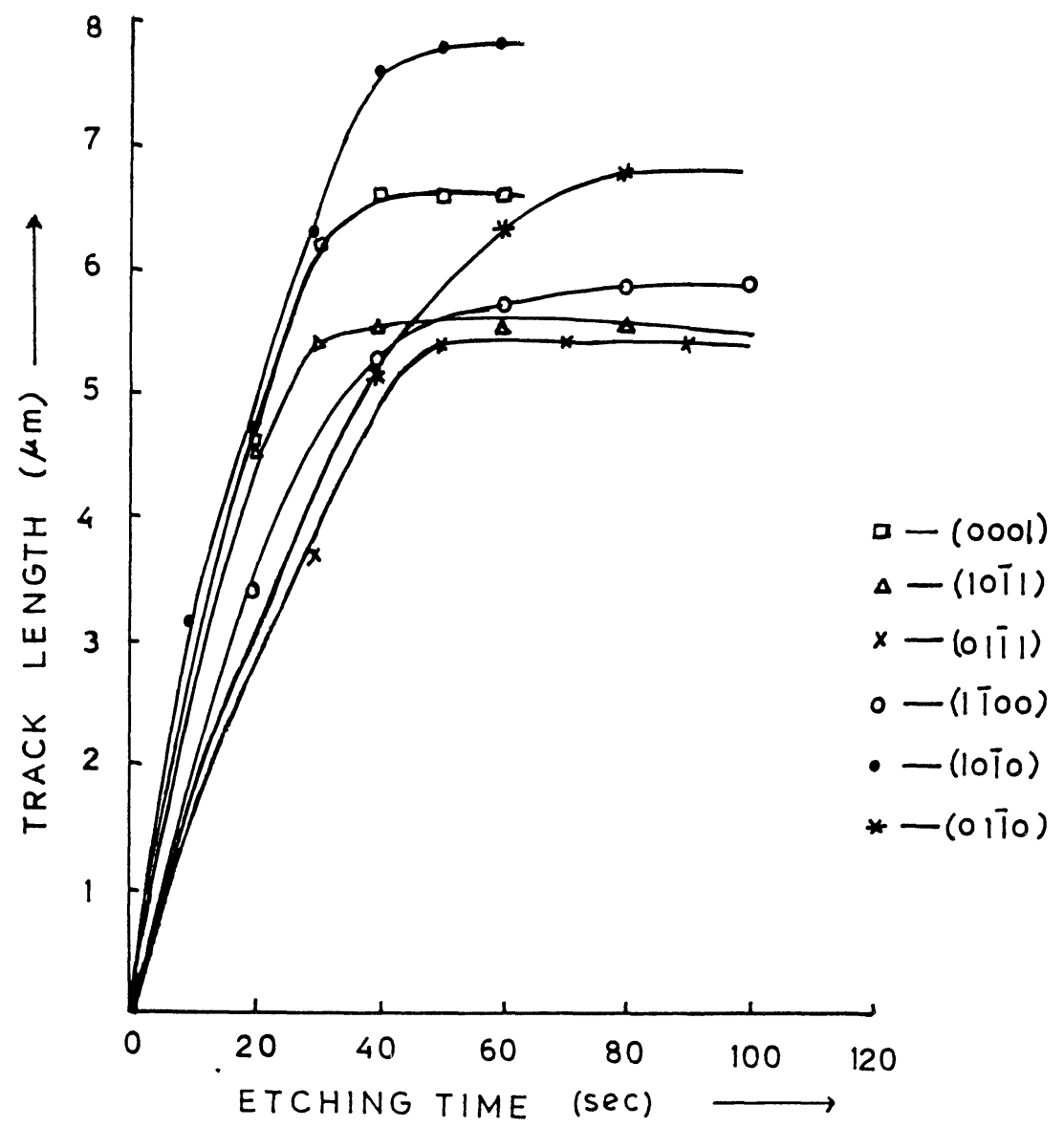

FIG. 2. The variation of track length with etching time for different planes of apatite crystal.

or $\mathrm{V}_{\mathrm{T}}=\frac{\Delta \mathrm{L}}{\Delta \mathrm{t}}$

Thus $\mathrm{V}_{\mathrm{T}}$ was determined from the slope of the linear part of the curve showing the variation of projected track length with etching time. The etching efficiency $(\eta)$ was calculated from the relation:

$$
\eta=1-\frac{\mathrm{V}_{\mathrm{G}}}{\mathrm{V}_{\mathrm{T}}} .
$$




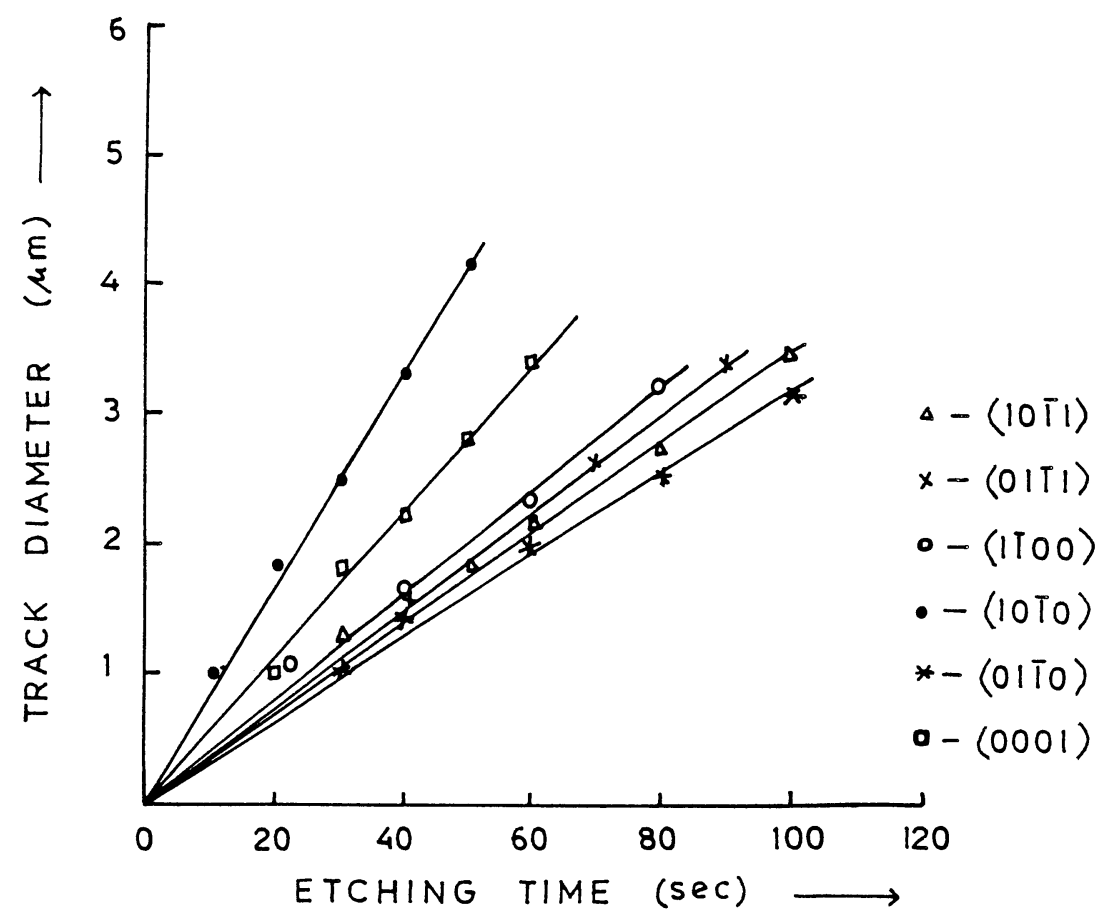

FIG. 3. The variation of track diameter (large diameter of ellipse i.e. major axis) with etching time for different planes.

TABLE 1. The value of $\mathrm{V}_{\mathrm{G}}, \mathrm{V}_{\mathrm{T}}$ and $\eta$ for different planes (faces) of apatite crystal.

$\begin{array}{lccc}\text { Face } & \begin{array}{c}\text { Track etch } \\ \text { rate } \mathrm{V}_{\mathrm{T}} \\ (\mu \mathrm{m} / \mathrm{sec})\end{array} & \begin{array}{c}\text { Bulk etch } \\ \text { rate } \mathrm{V}_{\mathrm{G}} \\ (\mu \mathrm{m} / \mathrm{sec})\end{array} & \begin{array}{c}\text { Etching } \\ \text { efficiency } \\ \left(\eta_{\%}\right)\end{array} \\ 1010 & 0.225 & 0.040 & 82.230 \\ 0111 & 0.120 & 0.020 & 83.330 \\ 1100 & 0.165 & 0.020 & 87.879 \\ 0001 & 0.230 & 0.027 & 88.044 \\ 01 \mathrm{~T} 0 & 0.135 & 0.015 & 88.880 \\ 10 \mathrm{~T} 1 & 0.200 & 0.019 & 90.630\end{array}$

The results for $\mathrm{V}_{\mathrm{G}}, \mathrm{V}_{\mathrm{T}}$ and $\eta$ for different planes are given in Table 1 .

(c) Standardization of etching conditions

In order to determine the optimum etching time for fossil tracks in apatite, a 
sample containing fossil tracks (Fig. 4) from (0111) plane was etched in $6 \% \mathrm{HNO}_{3}$ at room temperature for different time intervals and the track density was recorded corresponding to each time interval with the help of an Olympus binocular microscope at a magnification of $600 \mathrm{X}$. The track densities measured at different time intervals are shown in Fig. 5.

In order to find optimum etching time for induced fission tracks, the annealed apatite samples from different planes irradiated with thermal neutrons (from CIRUS Reactor at BARC Trombay with a dose of $5 \times 10^{14} \mathrm{nvt}$ ) were etched in $6 \% \mathrm{HNO}_{3}$ at room temperature for different time intervals. The induced track density was recorded at each etching interval for different planes. The results for the variation of track density with etching time for different planes are shown in Fig. 6.

Age determination on different planes of apatite crystal

The fission track method of age determination involves the sample preparation, thermal neutron irradiation, etching and scanning of the samples. In the present work we have used population method for age determination on different planes of the crystal. The samples from each plane were divided into two groups, one for fossil track (due to spontaneous fission of $\mathrm{U}^{238}$ ) and other for induced track (due to induced fission of $\mathrm{U}^{235}$ ) counting. The samples of different faces from the first group were etched in $6 \% \mathrm{HNO}_{3}$ for $44 \mathrm{sec}$ at room temperature. The tracks were then counted under an optical microscope at a magnification of $600 \times$. The samples of different

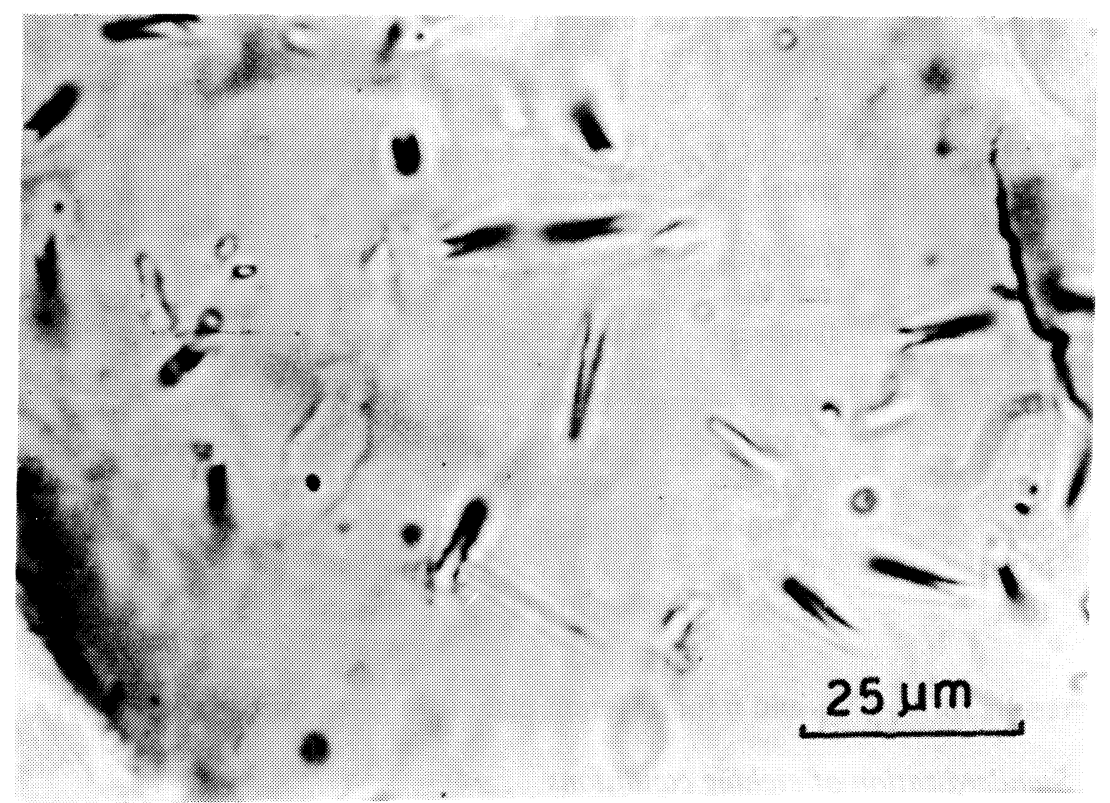

FIG. 4. Micro-photograph of fossil fission tracks in apatite. 


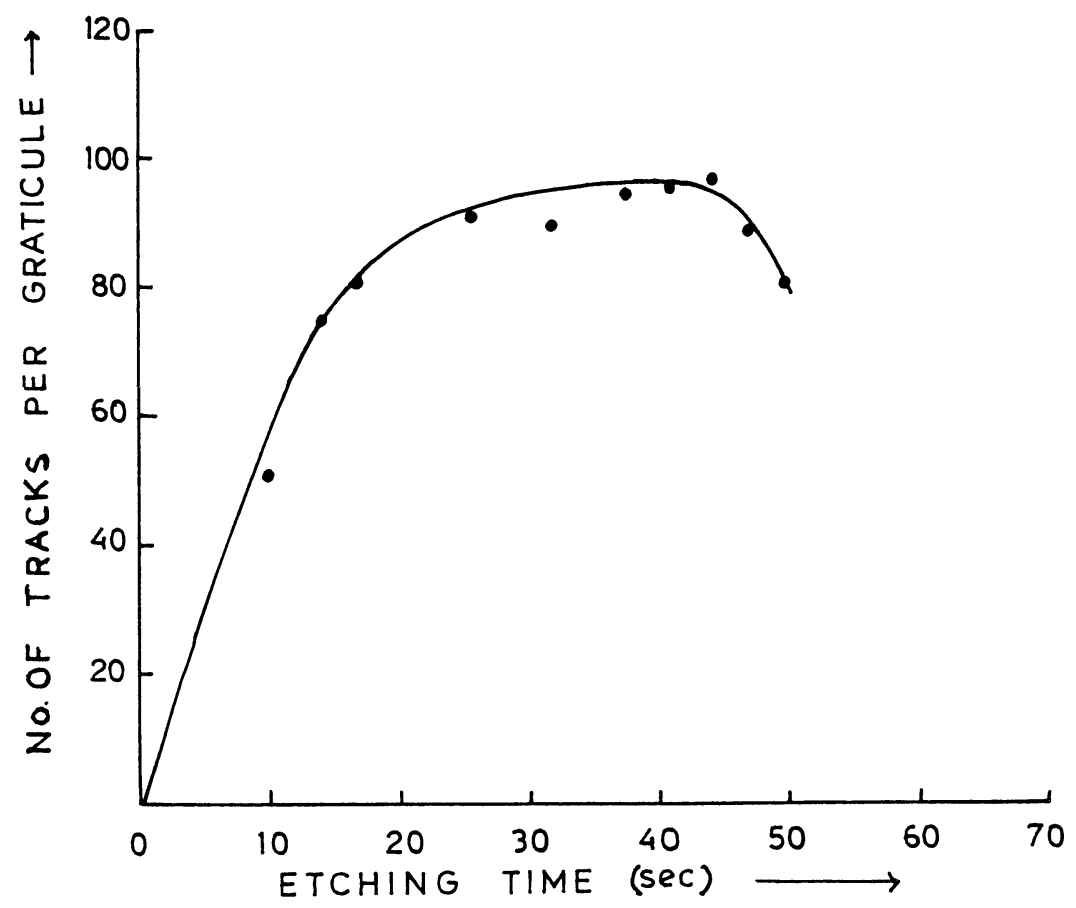

FIG. 5. The optimum etching time curve for fossil tracks.

planes from second group were heated in a muffle furnace at $530^{\circ} \mathrm{C}$ for one and a half hour to remove fossil tracks. These samples were then irradiated from a CIRUS Reactor of BARC Trombay with a total integral thermal neutron dose of $5 \times 10^{14}$ (nvt). The samples were then etched and the induced track density (which is due to induced fission of $\mathrm{U}^{235}$ ) was measured in each sample. The fission track age (T), on different planes of apatite was calculated by using the formula (Price and Walker, 1963; Fleischer et al., 1975; Singh and Virk, 1978; Virk and Singh, 1977):

$$
\mathrm{T}=\frac{1}{\lambda_{\mathrm{D}}} \ln \left(1+\frac{\lambda_{\mathrm{D}}}{\lambda_{\mathrm{F}}} \sigma \phi \frac{\rho_{\mathrm{S}}}{\rho_{\mathrm{i}}}\right)
$$

where $\lambda_{\mathrm{D}}=$ total decay constant of uranium $=1.54 \times 10^{-10} \mathrm{yr}^{-1}$

$\lambda_{\mathrm{F}}=$ fission decay constant for $\mathrm{U}^{238}=7.03 \times 10^{-17} \mathrm{yr}^{-1}$ (Robert et al., 1968)

$\sigma=$ cross-section for thermal neutron-induced fission of $\mathrm{U}^{235}=582 \times$ $10^{-24} \mathrm{~cm}^{2}$

$\phi=$ total thermal neutron dose $=5 \times 10^{14}$ (nvt) 


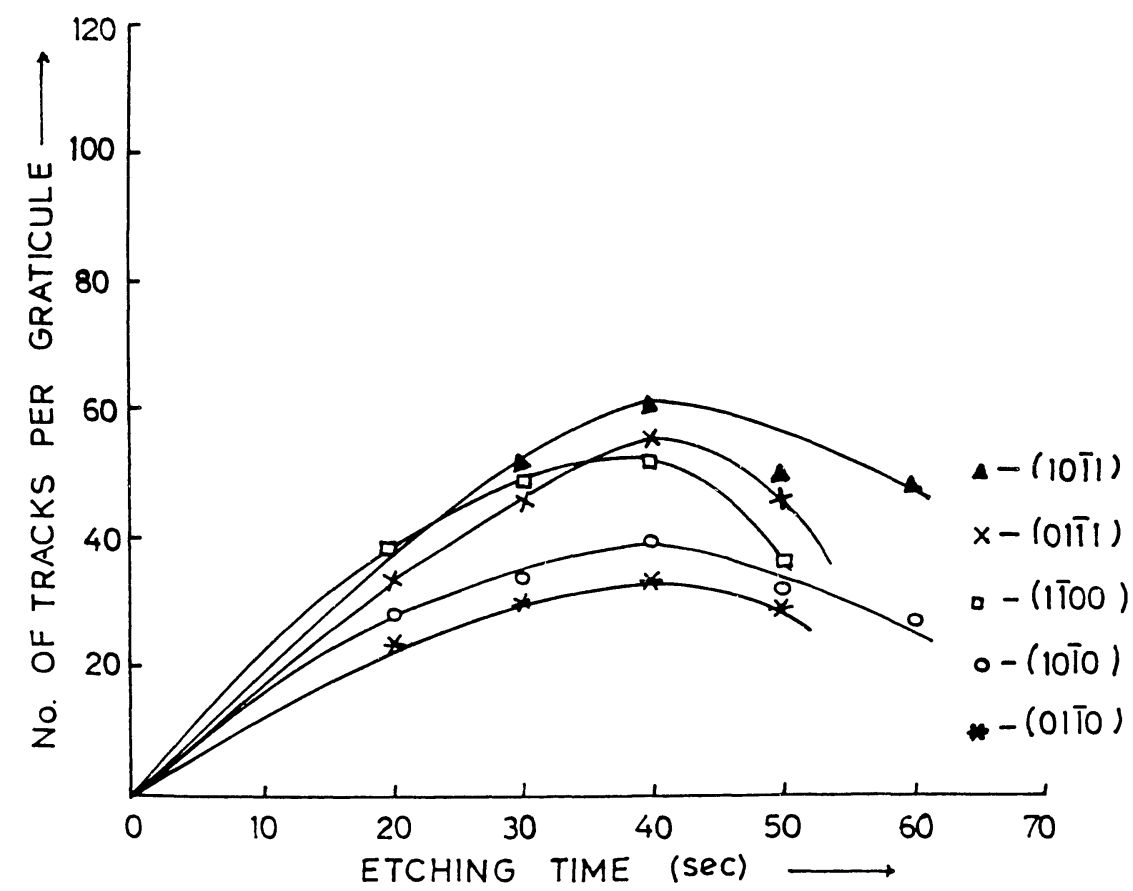

FIG. 6. The variation of number of induced tracks per graticule with etching time for different planes of apatite crystal.

$$
\mathrm{I}=\text { isotopic abundance ratio of } \mathrm{U}^{235} \text { to } \mathrm{U}^{238}=7.26 \times 10^{-3}
$$

$\rho_{\mathrm{S}}$ and $\rho_{\mathrm{i}}$ are the fossil and induced track densities respectively.

The thermal neutron dose used was calculated by measuring the track density (Fig. 7) in the standard glass dosimeter irradiated alongwith the samples. Thermal neutron dose is related with the track density $\left(\rho_{\mathrm{d}}\right)$ in dosimeter by the simple equation (Fleischer et al., 1965):

$$
\phi=\mathrm{k} \rho_{\mathrm{d}}
$$

where $\mathrm{k}$ is calibration constant. The value of $\mathrm{k}$ for GEC glass (supplied through the courtesy of Dr. R. L. Fleischer) with U. Content of 20 ppm used in the present work is $0.46 \times 10^{10}$ (Virk, 1980).

The results for fission track age determined on different planes using equation (4) are given in Table 2. 


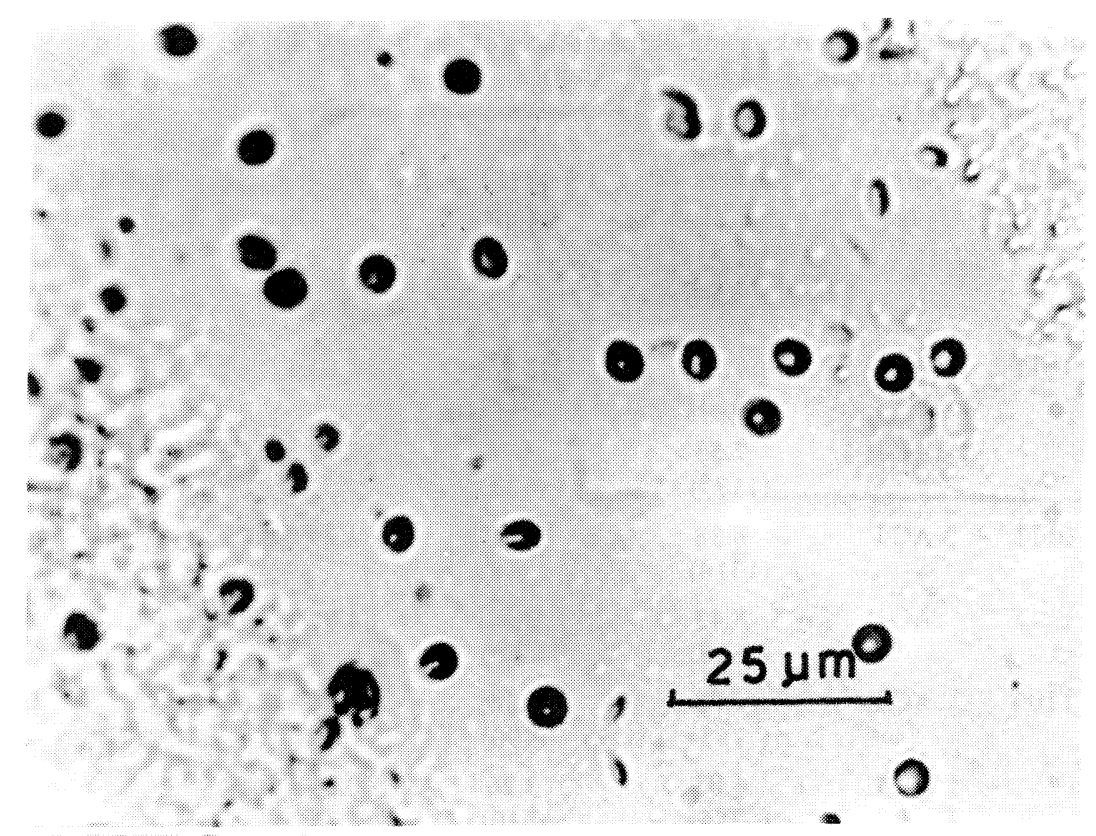

FIG. 7. Micro-photograph of induced fission tracks in glass dosimeter.

\section{Results and discussion}

The fossil track density (Fig. 5) in case of apatite increases with etching time becomes maximum and then decreases. The optimum etching time corresponding to maximum track density for fossil tracks is found to be $44 \mathrm{sec}$ for (0111) plane of apatite. The induced track density (Fig. 6) on various crystal faces shows similar behaviour of its variation with etching time. It has been found that the optimum etching time in case of samples containing induced fission tracks is less than that for fossil tracks. However it has been observed that the optimum etching time for induced tracks on different faces of apatite crystal is the same, though a slight variation of induced track density is found. Thus we conclude that spontaneous tracks etch more slowly than the induced tracks. Thus our results corroborate the findings of Reimer (1974) and Poupeau et al. (1980) for apatite. In both the fossil and induced samples the decrease in track density with prolonged etching may be due to overlapping of tracks or due to progressive removal of surface zone containing externally implanted tracks (Gleadow, 1978).

From Table (1) it is evident that $\mathrm{V}_{\mathrm{G}}, \mathrm{V}_{\mathrm{T}}$ and $\eta$ vary with the crystallographic orientations. This shows that track etching behaviour of apatite is anisotropic. The value of $\mathrm{V}_{\mathrm{T}}$ varies from $0.120 \mu \mathrm{m} / \mathrm{sec}$ for $01 \overline{1} 1$ plane to a maximum of $0.230 \mu \mathrm{m} / \mathrm{sec}$ 
TABLE 2. Fission track age on different faces of apatite crystal Thermal neutron dose $\phi=4.54 \times 10^{14}$ (nvt)

No. of tracks in the dosimeter $=1500$

\begin{tabular}{|c|c|c|c|c|c|}
\hline Face & $\begin{array}{c}\text { Sample } \\
\text { No. }\end{array}$ & $\begin{array}{c}\text { Fossil track } \\
\text { density } \\
\rho_{\mathrm{s}} \times 10^{-5} \\
\left(\text { Tracks } / \mathrm{cm}^{2} \text { ) }\right.\end{array}$ & $\begin{array}{c}\text { Induced track } \\
\text { density } \\
\rho_{\mathrm{i}} \times 10^{-5} \\
\left(\text { Tracks } / \mathrm{cm}^{2}\right)\end{array}$ & $\begin{array}{c}\text { Fission track } \\
\text { age } \\
\mathrm{T} \\
(\mathrm{Ma})\end{array}$ & Mean age \\
\hline \multirow[t]{2}{*}{$10 \mathrm{I} 1$} & AC-I & $\begin{array}{c}7.38 \\
(1153)^{*}\end{array}$ & $\begin{array}{c}3.95 \\
(618)\end{array}$ & $50.63 \pm 2.84 * *$ & \multirow{2}{*}{$50.87 \pm 2.84$} \\
\hline & AC-II & $\begin{array}{r}7.53 \\
(1177)\end{array}$ & $\begin{array}{c}3.98 \\
(623)\end{array}$ & $51.12 \pm 2.85$ & \\
\hline \multirow[t]{2}{*}{$01 \mathrm{I} 1$} & AC-I & $\begin{array}{r}8.38 \\
(1310)\end{array}$ & $\begin{array}{c}3.48 \\
(544)\end{array}$ & $64.29 \pm 3.67$ & \multirow{2}{*}{$64.63 \pm 3.68$} \\
\hline & AC-II & $\begin{array}{r}8.43 \\
(1318)\end{array}$ & $\begin{array}{c}3.52 \\
(550)\end{array}$ & $64.97 \pm 3.70$ & \\
\hline \multirow[t]{2}{*}{1100} & AC-I & $\begin{array}{c}4.83 \\
(755)\end{array}$ & $\begin{array}{c}3.13 \\
(490)\end{array}$ & $41.84 \pm 2.65$ & \multirow{2}{*}{$41.00 \pm 2.58$} \\
\hline & AC-II & $\begin{array}{r}4.83 \\
(755)\end{array}$ & $\begin{array}{c}3.26 \\
(510)\end{array}$ & $40.16 \pm 2.52$ & \\
\hline \multirow[t]{2}{*}{$10 \mathrm{~T} 0$} & AC-I & $\begin{array}{r}4.28 \\
(669)\end{array}$ & $\begin{array}{c}2.50 \\
(391)\end{array}$ & $46.45 \pm 3.18$ & \multirow{2}{*}{$46.59 \pm 3.20$} \\
\hline & AC-II & $\begin{array}{r}4.32 \\
(673)\end{array}$ & $\begin{array}{c}2.50 \\
(391)\end{array}$ & $46.73 \pm 3.21$ & \\
\hline \multirow[t]{2}{*}{0110} & AC-I & $\begin{array}{r}3.67 \\
(574)\end{array}$ & $\begin{array}{c}2.38 \\
(372)\end{array}$ & $41.91 \pm 3.00$ & \multirow{2}{*}{$42.27 \pm 2.80$} \\
\hline & AC-II & $\begin{array}{r}3.73 \\
(584)\end{array}$ & $\begin{array}{c}2.38 \\
(372)\end{array}$ & $42.63 \pm 3.06$ & \\
\hline \multicolumn{6}{|c|}{$* \mathrm{~N}=$ Numbers of tracks counted } \\
\hline$* * 1 \sigma=$ & $\begin{array}{l}\sigma_{S}^{2}+\sigma_{1}^{2}+ \\
=\frac{100}{},\end{array}$ & $=\frac{100}{\sqrt{\mathrm{N}_{\mathrm{i}}}}, \sigma_{\mathrm{d}}$ & $\frac{100}{\sqrt{N_{d}}}$ & & \\
\hline
\end{tabular}

for a plane perpendicular to $\mathrm{z}$-axis of the crystal. Similarly $\mathrm{V}_{\mathrm{G}}$ varies from 0.015 $\mu \mathrm{m} / \mathrm{sec}$ for $01 \overline{1} 0$ plane to $0.040 \mu \mathrm{m} / \mathrm{sec}$ for $10 \overline{1} 0$ plane. The etching efficiency $\eta$ varies from 82.23 to $90.63 \%$. The variation of $\mathrm{V}_{\mathrm{G}}$ and $\mathrm{V}_{\mathrm{T}}$ with the crystallographic orientation may be due to the variable atomic spacing along different orientations in the crystal. The detailed X-ray work is needed to establish this fact. The work on anisotropy in the direction at one crystal surface has already been reported by Khan (1977), Begalli et al. (1984), and Laslett et al. (1984) for crystalline track detectors. 
The work on the anisotropic etching behaviour on the angular distribution of tracks in case of apatite is in progress in our laboratory.

The f.t. age (Table 2) determined on different planes of apatite crystal is found to vary from $41.00 \pm 2.58$ to $64.63 \pm 3.68$ m.y. However it has been observed that the samples from the same face give almost the same age. The large variation in the observed age with crystallographic orientations is due to the anisotropy of track etching in the crystal. It is necessary to determine the f.t. age on different planes of the crystal in order to get an accurate age.

The errors shown in the results are the $(1 \sigma)$ statistical counting errors based on the number of tracks counted in the fossil, induced and glass dosimeter samples.

\section{Conclusions}

1. The track etching behaviour of apatite is anisotropic.

2. Fission track age should be determined on different planes of the crystal to get an accurate age.

Acknowledgements-The authors acknowledge the financial assistance of CSIR. They are thankful to Mr. Jagmohan Singh for preparation of the samples.

\section{References}

BEgAlli, M., MARQUES, A. and SERRA, D. A. B. (1984) Nucl. Tracks, 9, 129-138.

DURRANI, S. A., KHAN, H. A., BUll, R. K., DORling, G. W. and FREMLIN, J. H. (1974) Proc. 5th Lunar Sci. Conf., Geochim. Cosmochim. Acta Suppl., 5, 2543-2560.

FlEISCHER, R. L., PRICE, P. B. and WALKER, R. M. (1965) Nucl. Sci. Eng., 22, 153-156.

FLEISCHER, R. L., PRICE, P. B. and WALKER, R. M. (1975) Nuclear Tracks in Solids, Principles and Applications, University of California Press, Barkeley, U.S.A.

GLEADOW, A. J. W. (1978) Nucl. Track Det., 2, 105-117.

KHAN, H. A. (1977) Rad. Effects, 32, 49-53.

LASlEtT, G. M., GLEADOW, A. J. W. and DUDDY, I. R. (1984) Nucl. Tracks, 9, 29-38.

NAGPAUL, K. K. (1974) Recent Researches in Geology. Hindustan Publ. Corp., Delhi, 41-52.

Poupeau, G., CARpena, J., Maihle, D. and CEYlan, V. K. (1980) C.R. Acad. Sci. Paris, 290 (D), 1189-1192.

PRICE, P. B. and WALKER, R. M. (1962) Journ. Appl. Phys., 33, 3407-3412.

PRICE, P. B. and WALKER, R. M. (1963) Journ. Geophys. Res., 68, 4847-4862.

REIMER, G. M. (1974) Trans. Amer. Nucl. Soc., 18, 87-90.

Robert, J. H., Gold, R. and ARMANI, R. J. (1968) Phys. Rev., 174, 1482-1484.

SINGH, S. and VIRK, H. S. (1978) Geochem. Journ., 12, 271-274.

SINGH, N. P., SINGH, M., SINGH, S. and VIRK, H. S. (1984) Nucl. Tracks and Rad. Measurements, 8, 41-44.

VIRK, H. S. and SINGH, S. (1977) Miner. Journ., 8, 263-271.

VIRK, H. S. (1980) Int. Journ. Appl. Rad. and Isotopes, 31, 649-651.

Received August 24, 1985; revised February 1, 1986. 